C.I.F. T. XIV (1988), págs. 21-39

\title{
AMOR Y HOMOSEXUALIDAD EN JUAN GIL-ALBERT
}

\author{
Carmen Peña Ardid* \\ Colegio Universitario de Teruel
}

\author{
Ese secreto de Dios inscrito \\ en mi sangre... (A. Gide)
}

\begin{abstract}
RESUMEN
El propósito de Juan Gil-Albert al desarrollar en Heraclés el tema de la condición homosexual es substraerlo al desconocimiento voluntario y aun al «malditismo» en que ha sido mantenido el problema durante siglos. En el presente estudio se intentan analizar las raices éticas y pedagógicas desde las que el autor contempla los fundamentos del amor viril, persiguiendo la prolongación de estas ideas en tres obras clave dentro de su producción prosística: Valentín, Razonamiento inagotable y Los Arcángeles.
\end{abstract}

\section{RESUMÉ}

En traitant dans Heraclés le thème de la condition homosexuelle, Juan GilAlbert veut le soustraire à la méconnaissance volontaire et même au «malditisme» dans lequel ce problème a été circonscrit pendant des siècles. Dans cette étude on essaie d'analyser les sources éthiques et pédagogiques à partir desquelles l'auteur envisage les fondements de l'amour viril, poursuivant la réelaboration de ces idées dans trois oeuvres capitales de sa production en prose: Valentín, Razonamiento inagotable et Los Arcángeles.

Ha sido frecuente reconocer en la obra de Juan Gil-Albert el modelo de un escritor profundamente moralista a la usanza clásica. Lo peculiar de esta «anacrónica»’ actitud

* Licenciada en Literatura Española. Dpto. de Filología Española, Colegio Universitario de Teruel, Apartado 1; 44080 Teruel. Recibido el 27-1-88.

1. Cf. el artículo de Jaime GIL DE BIEDMA, «Un español que razona» Calle del Aire, «A Juan Gil-Albert», Sevilla, 1977, p. 47. Y el propio autor, en una entrevista con F. G. DELGADO, asume lo de moralista «en el sentido que le cuadra a Montaigne... un moralista «ad libitum», lo que se llama corrientemente moral en las sociedades constituidas más bien me subleva...» («Juan Gil-Albert después del silencio», Insula, n. ${ }^{\circ} 350$, enero, 1976, pp. 4-5). 
sorprende aún más por el hecho de que no es el comportamiento social, sino la «ética individual», lo que constituye el eje de la reflexión gilalbertiana ${ }^{\text {? }}$ : «L que cuenta en el hombre -dirá en Cantos rodados- es su vida privada, lo que él se siente ser...» ${ }^{3}$. Las preocupaciones educadoras de Gil-Albert se materializan, en su obra prosística, mediante la adopción de distintas modalidades de la autobiografía, pero también en el despliegue de una retórica discursiva que revela, de forma explícita, las intenciones didácticas del autor, su deseo de reanudar una antigua aspiración a «servir de guía» y conservar el concepto de «ejemplaridad individual» $\aleph^{4}$.

Entre los precedentes de esta posición moralista a los que se vincularía Gil-Albert ${ }^{5}$, ha llamado la atención de la crítica su rescate de las viejas inquietudes pedagógicas de la filosofía helénica, que hereda de la poesía arcaica el interés por las posibilidades de la paideia, proponiéndose, ya con Sócrates y Platón, «el desarrollo del hombre dentro del hombre»". Gil-Albert reaviva el legado griego -sustento de sus ideas, en muchos aspectos- asumiendo como constantes de su obra el problema de la realización personal, la búsqueda del perfeccionamiento del hombre a través de la cultura y de las enseñanzas extraídas del acontecer vital, y, en definitiva, lejos de la elaboración de preceptos, formula el problema de la paideia como el de las relaciones (o la lucha) del hombre con «lo viviente»?

Un tema de gran importancia dentro de la creación literaria del escritor alicantino y, tal vez, el más enraizado en esta perspectiva moral, es el problema de la homosexualidad. Heraclés ${ }^{8}$ es la obra que el autor dedica, específicamente, al tema de la condición homoerótica. Se trata de un ensayo en el que lo autobiográfico, aparentemente, cede terreno a una reflexión menos personalizada y anecdótica, pero nunca desligada intelectual y pasionalmente del escritor. No estamos ante un «frío tratado científico», apunta Luis Antonio de Villena, sino ante «el primer tratado humanístico sobre la homosexualidad en nuestra lengua» ${ }^{9}$. A pesar de ello, en el prólogo escrito en 1975, afirma Gil-

2. La herencia de André Gide es definitoria en este punto, siendo reconocida también por Gil-Albert: «Gide ha sido sin duda ninguna, mi gran escuela formativa, moral y literaria» (en el artículo de Jaime MILLAS, «Juan Gil-Albert, un poeta isla», Triunfo, 27 de julio. 1974, entrevista). Sobre la influencia temprana del modelo ético de Gide en el compromiso social del autor durante los años de la guerra civil, véase el prólogo de Manuel AZNAR SOLER al libro de poemas de Gil-Albert, Mi voz comprometida (1936-1939), Barcelona, Ed. Laia, 1980, pp. 32-3.

3. Cantos rodados, Barcelona, Ambito, 1976, p. 45. Esta preferencia no implica que los problemas de índole política o social estén ausentes de su obra. Lo atestiguan libros como Drama patrio (1964) o Los dias están contados (1974), aunque también en ellos el acento recaiga sobre la repercusión de los social en el individuo. Un análisis amplio de las dos facetas del autor, la intimista y la social, en el ámbito de su creación poética, lo realiza Francisco BRINES, «La tierra natal en la poesía de Juan Gil-Albert», Calle del Aire, Sevilla, 1977, pp. 187-275.

4. La referencia a esta doble pretensión la encontramos en muchas de sus obras. Véase Concierto en mi menor, incluido en Memorabilia, Barcelona, Tusquets, 1975, p.15; Los dias están contados, Barcelona, Tusquets, 1974, p. 129, o Crónica General, Barcelona, Seix Barral, 1974, p. 41.

5. Además de André Gide, Montaigne, en primer lugar, pero también Rousseau, Nietzsche, San Agustín, Santa Teresa o, incluso, Unamuno.

6. Cf. José S. LASSO DE LA VEGA, «El eros pedagógico de Platón», en la obra de conjunto, El descubrimiento del amor en Grecia, Madrid, Ed. Coloquio, 1985, pp. 106-108. Para el tema de Sócrates como «médico del hombre interior», cf. Werner JAEGER, Paideia, Méjico, Fondo de Cultura Económica, 1981, sexta reimpr. pp. 389-457.

7. En el poema «La Ambición», perteneciente a Los Homenajes, el poeta expresa su deseo de identificarse con el Centauro Quirón, educador de Aquiles, Jasón, Asclepio y Apolo. Pedro J. de la PEÑA considera estos versos como un auténtico autorretrato del autor (Juan Gil-Albert, Madrid, Ed. Júcar, 1981, p. 14).

8. Heraclés, Madrid, Taller de Ediciones J.B., 1975. Según explica el autor en el prólogo, la obra estaría escrita en 1955, veinte años antes de su publicación.

9. Para Villena, esta perspectiva vitalista, cultural y humana de Heraclés lo convierte en un libro muy superior al Corydon de Gide, mucho más plegado a los prejuicios positivistas de la ciencia. 
Albert que la «falta de amenidad» de Heraclés es, justamente, lo que le ha hecho decidirse a publicarlo, «porque me hace sospechar que sólo los que deben leerlo, lo lean. Máximo contentamiento para quien huye, con igual recelo de la publicidad y de la ocultación» (H. pág. 11).

Estas palabras - tan ajustadas, por otra parte, a su actitud como escritor-ponen de manifiesto una clara voluntad de emplear un discurso y un tono «diferentes» para el tratamiento de una cuestión tradicionalmente problemática. Pero, además, coinciden con la opción personal de Gil-Albert - paralela a la de un André Gide o un Cocteau-, en su rechazo de algunas actitudes muy frecuentes en el ámbito homosexual literario, las que Hans Mayer define como de «doble vida», vacilante entre la sinceridad y el escándalo ${ }^{10}$. Si en Crónica General, el escritor alicantino sostiene que su «inserción en la sociedad» tenía que ser «plena y abierta, sin ocultaciones... dueña de su destino» (C.G. pág. 509), en Heraclés perfila más las complejidades de la autoafirmación pública:

La reserva bordeará el peligro de la hipocresía; la sinceridad estará, en cambio expuesta al cinismo. $\mathrm{Y}$ entre ambos se deformará muchas veces, por defecto o por exceso, la integridad homosexual... Atreverse a confesar lo que se es y no utilizar esta confesión como patente de relajamiento ni, a la vez, de arrepentimiento, es la pauta sobre la que ha de inscribir su ritmo mesurado (H. pág. 130).

Quizás esto explique que Gil-Albert establezca un cierto distanciamiento a la hora de tratar esta modalidad erótica. Cuando el tema reaparece, como trasunto novelesco, en tres obras fundamentales del autor: I'alentin, Razonamiento inagotable con una carta final y Los Arcángeles" ", no puede pasarnos por alto el hecho de que lo haga bajo la forma de la autobiografia ficticia, especialmente porque son tres excepciones en el conjunto de la creación gilalbertiana.

El objeto de nuestro estudio es contemplar estas obras a la luz del texto teórico que es Heraclés, y determinar cómo se plasman los caracteres de la condición homosexual, así como la filosofía del amor allí expuesta, en el conflicto vivencial de unos personajes implicados en una peripecia anecdótica. Es cierto que tales ficciones se acogen a la fórmula «meditativo autobiográfica», común a toda la prosa del autor, lo que las aproxima, en muchos aspectos a la dimensión del «tratado» ${ }^{2}$, pero las historias narradas tienen

(«Heraclés invoca a Hylas», Papeles de Son Armadans, n. ${ }^{\circ}$ CCXLIII, junio 1976, p.323). Cf. también Antonio ROMERO MARQUEZ, «Heraclés, Gil-Albert nos pone a prueba», Insula, núms. 356-357, julio-agosto 1976, p. 18.

10. Hans MAYER, Historia maldita de la literatura (La mujer, el homosexual y el judio), Madrid, Taurus, 1977, p. 190. Ilustres nombres de la literatura aparecen manteniendo una línea de ocultamiento o de estilización: Winckelmann, Platen, Whitman, Proust, Oscar Wilde...

11. Valentín, Barcelona, La Gaya Ciencia, 1974, se había escrito mucho antes, en 1964, al igual que Razonamiento... Madrid, Caballo Griego para la Poesía, 1979, escrita en 1976. Los Arcángeles, Barcelona, Laia, 1981, también es remitida, en un prólogo anónimo, a una fecha anterior a 1970. Si el retraso en la publicación de sus obras ha sido una constante para Gil-Albert, en el caso de las que nos ocupan, el escritor alicantino esperaría los momentos más propicios para darlas a la luz. Es interesante, sin embargo, advertir el enmascaramiento que las envuelve, de acuerdo con un sistema nada habitual en el autor. En Valentín, la distancia autor/personaje se crea al situarse la acción en la época de Shakespeare, pero en Razonamiento... además de incluirse el propio Gil-Albert en las últimas páginas de la obra, aparece una «nota del autor» en la que se habla del carácter «inventado» de todos los personajes, y se niega tajantemente cualquier vinculación con el escritor. En Los Arcángeles, quizá por tratarse de un homenaje a Gide, se recurre incluso a la fícción del manuscrito entregado al editor por un amigo ya muerto. En todo caso el enlace de estas obras al orbe gilalbertiano no procede de lo anecdótico, sino del pensamiento de los personajes y de la estructura artística que lo vehicula. Partiendo de un episodio autobiográfico, sin embargo, parece configurarse la última obra de Gil-Albert, Tobeyo (Homenaje a México) -según nuestras noticias todavía inédita-, a la que se hacen numerosas referencias en Cartas a un amigo, Valencia, Pre-textos, coedición con el Instituto de Estudios «Juan Gil-Albert», 1978.

12. Gil-Albert insiste, concretamente, en que Valentin «no es un suceso, es un Tratado». Cf. Luisa CAPECCHI, «El tratado de amor de Valentín», L'Arrel «A Juan Gil-Albert», verano-otoño, 1981, pp. 35-40. 
la suficiente consistencia como para que puedan leerse, diríamos, como distintos «casos de amor». Richard, Diego, Claudio, sus protagonistas, encarnan problemáticas diversas, no sólo frente al fenómeno amoroso en sí, sino también, en cuanto a la aceptación de su identidad y al acatamiento de sus exigencias.

\section{HERACLES: LA HOMOSEXUALIDAD COMO MODELO VITAL}

El tema del amor viril no es en Heraclés sino un aspecto de un propósito más vasto: desentrañar la «trama intelectual y emocional» de quienes son llamados a él, y desvelar los componentes éticos y estéticos que atañen el proceder homosexual. Contemplada en su excepcionalidad -dados los obstáculos personales y sociales a los que se enfrenta- la condición homosexual adquiere un carácter de distintivo heroico que es preciso conocer y educar: «Nacer homosexual es llevar en sí, inherente a la misma virtud de vida, el principio de un obligatorio destino», que sitúa a los así definidos, «en un plano especial de experiencia y de desarrollo» $(\mathrm{H}$. pág. 169). El punto de partida será la asunción de la propia naturaleza, evitando la «humillación del ser» llevada a cabo por los que, al reconocerse en su peculiaridad, creen estar «delinquiendo» en su propio ser ${ }^{13}$, y el punto de llegada la autoafirmación personal con el acatamiento -y sublimación- del destino no menos singular que les corresponde. Gil-Albert trazará en Heraclés un auténtico "camino de perfección», que habrán de recorrer también, con sus zozobras y sus delirios, los personajes ficticios:

¿Pero el homosexualismo no podría ser, en el mejor de los casos, un proyecto? ¿Un intento conjunto de alma y cuerpo, de soma y psiquis, de ser, en el plano de las realizaciones humanas, otra cosa, un ser distinto, una definitiva variedad? (H. pág. 105).

El pensamiento de Gil-Albert conserva aquí algunos rasgos del aristocratismo que se concedía en ciertos círculos griegos al amor masculino, entendido como «expresión más pura del eros» ${ }^{1+} \mathrm{e}$, incluso, como una forma superior de amor. Pero se proyecta, sobre todo, en un sentido ético, revistiendo lo «distintivo» con los apremios de una misión particular, ya que la trayectoria homosexual se cumple al margen de los caminos amorosos habituales y de la forma de convivencia que implican. Es en este ámbito donde la tarea de formación del individuo y la necesidad de «servir de guía» resulta perentoria para Gil-Albert, si bien con la posibilidad abierta de ser aplicada al hombre en general, al menos en cuanto labor de autoconocimiento. Específicamente, se trata de hablar a los «desorientados», que no hallan «ni una palabra útil, ni un consejo utilizable, nada; por el contrario, convencionalismos, hipocresias, subterfugios...» (H. pág. 105). Asi se escucha la patética queja de Richard, en latentin que, en el contexto de su tragedia, alude a la falta de un modelo en quien configurarse:

13. André Gide había puesto también en boca de Menalcas, personaje de El inmoralista, una condena similar: «Pero casi todos piensan que no obtendrán de sí mismos nada bueno si no es por la sujeción; sólo se gustan contrahechos. Cada uno pretende parecerse lo menos posible a sí mismo... Lo que se siente en uno de distinto es, precisamente, lo que se posee de raro, lo que da a cada cual su valor» (Madrid, Argos Vergara, 1981, p. 101).

14. Cf. José S. LASSO DE LA VEGA «El amor dorio», El descubrimiento del amor en Grecia, op. cit. p. 62. La interrelación que establece Francisco BRINES (art. cit., p. 196) entre homosexualidad y acercamiento al mundo griego en Gil-Albert, la encontramos también en Gide, en Lecal's's of Grass de Whitman, o en la Epistola in carcere et vinculis de Wilde, si bien en Gil-Albert, esta referencia tan afín a su ascendencia mediterránea, supone asumir también, como Gide, la visión del amor viril en sus componentes pedagógicos. Véase tambien F. BUFFIERE, Eros adolescent: la pédérastie dans la Grèce antique, París, 1980. 
iAh laberinto del alma del hombre... ¿por qué derroteros equivocados nos vemos impelidos, o en qué inesperadas encrucijadas se nos abandona, sin que una voz clara como la tarde de verano, nos inspire la renuncia justa o la aceptación pertinente? (V. pág. $87)^{15}$.

Esta es la voz que Diego, en Razonamiento inagotable, quiere ser para el joven Delfín, aunque éste, finalmente, quede solo ante su primer tropiezo de enamorado (R.I., págs. 105-107).

El contenido de Heraclés no se acoge a una rigurosa sistematización, pero cada uno de sus tres capítulos, precedidos, a modo de obertura, por la historia de Hylas, el joven amado de Heraclés, desarrolla una dimensión distinta de la problemática homosexual -al hilo de las citas de Pascal, Goethe y Shakespeare-, que veremos igualmente expuesta en los personajes literarios.

\section{Le propre de chaque chose doit être cherché (Pascal)}

En la primera parte traza Gil-Albert los avatares históricos del homosexualismo ${ }^{16}$ y va enunciando ya en su recorrido algunos principios caracterizadores de la condición homoerótica. El amor homosexual es definido, en primer lugar, por su exclusivismo. Esta premisa -objeto de una larga reflexión en Razonamiento inagotable $e^{17}$ - alejará, en tal aspecto, la concepción gilalbertiana de la «armoniosa ambigüedad helénica», que simultaneaba, como manifestación social, el eros viril con la vida familiar. No obstante, el principio sobre el que se levantan los fundamentos éticos del uranismo en Heraclés es la afirmación de que el homosexualismo es una naturale $z a^{18}$ : como ser hombre o ser mujer, ser homosexual es algo sustantivo, «una manera sustancial de ser hombre» (H. pág. 48). De aquí parte un consejo similar al «sé como eres» pindárico: «La responsabilidad de ser lo que se es» (H. pág. 44). Se comprende también qué especie de moralidad afecta al proceder homosexual; la que parte de la aceptación plena, pues para Gil-Albert «moral es, dentro del marco de una vida auténticamente sentida, toda determinación del espíritu sobre algo que está enraizado en nuestra carne» (H. pág. 55).

\section{La naturaleza sigue su marcha... y hasta lo que nos parece excepción obedece a} reglas (Goethe)

Este capítulo encierra una profundización mayor en los dominios de la ética, en el intento de determinar qué exigencias lleva implícitas la naturaleza homosexual y en qué dirección ha de desplegarse su personalidad. La «regla», para Gil-Albert, es no malograr-

15. Cf. Heraclés, pp. 80-1.

16. El punto en el que Gil-Albert detiene su recorrido histórico es el que se retoma en la obra de John LAURITSEN y David THORSTAD, Los primeros movimientos en favor de los derechos homosexuales (1864-1935), Barcelona, Tusquets, 1977, que mencionamos por estar prolongada, en la edición española, por el propio Gil-Albert.

17. El protagonista y narrador de esta obra, Diego, desde su madurez, introducirá en el joven Delfín la exigencia de respetar la autenticidad de sus relaciones amorosas, y de no prestarse a la impostura de recibir, por halago, el afecto femenino. El principio de la ética gilalbertiana implica el deber de no arrastrar a la mujer, o a otro ser, hacia la falsedad. Tema que volverá a repetirse en relación con otro personaje, Jaime, cuya amistad con Delfín no constituye en él una especificidad amorosa, sino una excepción.

18. Al igual que Pascal escribiría: «Tous les goûts son dans la Nature», para Gil-Albert «la vida contiene tantas manifestaciones como posibilidades» $(H$. p. 35). La crítica de la moral tradicional y, especialmente, de la moral cristiana que mutila las posibilidades del hombre, lo aproxima también a la figura de Nietzsche, en su afirmación de lo vital. José Carlos ROVIRA menciona al filósofo como «auténtico dinamizador de la cultura de Gil-Albert», «Las incesantes ilusiones de Gil-Albert», L'Arrel, revista cit., pp. 86-7. 
se, y el riesgo «deteriorar la condición viril». El soporte autobiográfico de las ideas aquí recogidas aparece especialmente en el esfuerzo del autor por reformular las incertidumbres e interrogantes que tempranamente asaltan a quienes se reconocen distintos. El homosexual «tiene que inventar, como profesión incomparable, su vida. Pocos lo consiguen, dado lo desconcertante de la empresa...» (H. pág. 105). Pero un paralelismo más estrecho se puede establecer entre el desarrollo auto-biográfico de la obra gilalbertiana y el estímulo que -se dice en Heraclés- siente el homosexual, al despertarse su conciencia, hacia la «introspección de sí mismo, preocupación intelectual de su yo, atención alerta hacia su propia persona» $(\mathrm{H}$. pág. 127), y ello como consecuencia de ser una naturaleza existencial y conflictiva. Aquí reside el carácter heroico de esta empresa realizada en solitario.

Muy amplia será la gama de los derrotados, tanto los que se mixtifican -caso de Richard, aunque luego halle su dignidad en la confesión-, como los que, conociéndose, se pliegan a las conveniencias sociales de la vida familiar, o los que intentando remedar el modelo femenino se desvirtúan. Sólo los que aceptan «el paradójico destino que les impone su pubertad, realizan el ideal de su casta» (H. pág. 106).

Traspasando el umbral de lo íntimo, enumera Gil-Albert algunos rasgos psiquicos, temperamentales y sociales del homosexual, que afloran en su comportamiento externo, y que nos son bien conocidos a través de la tradición literaria: la sensibilidad, la ociosidad introspectiva y contemplativa, la tendencia al equilibrio, el rechazo de la mujer -siendo, al mismo tiempo, sus máximos dignificadores ${ }^{19}-y$, finalmente, su predisposición para percibir la belleza: «son estetas de nacimiento» (H. pág. 168) ${ }^{20}$. Lo que les llevará, como veremos, no sólo a guiarse por un proceder similar al del artista, sino a estar expuestos, como, de nuevo, Richard ejemplificará con su trágico destino, a confundir el arte y la vida.

\section{Speak of me as I am (Shakespeare)}

El hombre se pone a prueba ante las inesperadas manifestaciones de la vida y el homosexual, de un modo más determinante, ante la experiencia del amor. Es significativo que Gil-Albert aborde el tema del amor viril tras haber afirmado que el conocimiento debe ser la consecuencia de toda «experiencia viviente» (H. pág. 137). En el proceso formativo del hombre -siempre que se revista la experiencia «con el sentido de la sabiduría»-, la llamada educación sentimental ha desempeñado tradicionalmente un papel clave que se rastrea ya en los himnos pindáricos o en las elegías de Teognis y Alceo. De esta tradición lírica, tanto como de la socrático/platónica toma Gil-Albert algunos de los principios de su filosofía del amor, sobre todo al entenderlo como

19. Gil-Albert aborda con gran amplitud en Heraclés esta afirmación de Gide: «Y así como el respeto a la mujer acompaña por lo general al uranismo, vemos menos honrada a la mujer en cuanto es más generalmente deseada. Comprenda usted que esto es natural», Corydon, Madrid, Alianza, 1979 , p. 158 (Cf. Heraclés, pp. 116-120).

20. El esteticismo con el que el homosexual reviste su existencia ha servido, al menos desde el siglo XIX hasta fechas recientes, casi como única forma de que esta manifestación fuera «tolerada» en las sociedades burguesas. El otro camino, es sabido, era el malditismo, el «outlaw» por el que Genet, entre otros, opta en sus comienzos. La fuente inicial vuelve a ser, sin embargo, el legado griego. 
«aventura pedagógica»" ${ }^{21}$. En primer lugar, el amor que Claudio en Los Arćangeles define como «la más intensa prueba viviente de la creación, su mordisco más apremiante, su picadura más incisiva» (L.A., pág. 14), puede llevar al conocimiento ${ }^{22}$. Por otro lado, entre los atributos educadores de Eros, vemos a Platón defender en Fedro la «manía» amorosa como una categoría superior de locura, pues sólo el amor «procura de nuevo al alma, la integridad, un día perdida, de su naturaleza» ${ }^{23}$. También Richard habla del animae dimidium meae (V. pág. 70), y Gil-Albert en Heraclés describe el enamoramiento como un acto de afirmación: «Lo que buscamos es, ser; eso parece, un empeño originario: una afirmación: nacer. Nacer a una vida plena en los brazos violentos de la fugacidad» (H. pág. 146).

La descripción que hace Gil-Albert de la vivencia homosexual del amor y del carácter trastornador y convulsivo que adquiere, en unos seres de intensa vida interior que se desenvuelven al margen de la «normalidad», alcanza su dimensión fundamental en los conflictivos personajes de Valentín, Razonamiento inagotable y Los Arcángeles, que habrán de enfrentarse, en última instancia, con el problema de la fugacidad inherente a toda manifestación amorosa.

Importa ahora constatar el grado de sublimación al que llega el autor cuando subraya la cohesión existente en el homosexual entre «instinto y espiritualidad». ¿Qué persiguen estos seres? ¿Cuál es la razón última de su elección amorosa que excluye a la mujer? Para Gil-Albert, se trata de no participar en la procreación, de no abdicar de la «soledad esencial», de no perderse en el discurrir transitorio de la existencia. Lo que en el dominio platónico era un deseo de "procrear en la virtud», buscando un alma bella en la que engendrar, lo asume Gil-Albert, pero más que en términos de areté, en el sentido de un ideal estético. El artista y el homosexual comparten un idéntico amor hacia la belleza y se esfuerzan desesperadamente por «paralizar lo que está en trance de desaparición»; buscan el ser a través de lo transitorio ${ }^{24}$. Y a ambos les une también la modelación de su destino «al margen sin duda de la moral que consuela, pero irremediablemente acogidos a la estética que templa y que, en otro plano que la moral, educa» $(\mathrm{H}$. pág. 183).

Para Gil-Albert, la «locura» del artista es de un grado tan alto como la amorosa y también posee ese poder integrador de las potencias humanas en el que tanto insistieron los románticos alemanes. De su potencialidad educadora nos habla Diego, en Razonamiento inagotable:

(...) sigo considerando a la estética como el medio más noble de la educación humana, entendiendo por educación el desarrollo más profundo y más clarividente de la especie animal llamada hombre... Ni coarta como la moral ni inhumaniza como la ciencia. La estética ha sido el descubrimiento humano que consigue unificar en el hombre, de un solo soplo, las acciones del corazón, de la inteligencia y de la sensibilidad. (R.I. pág. 45).

21. «Lo específico de la pederastia griega -señala LASSO DE LA VEGA- más que en su extensión en las costumbres de aquel pueblo, radica en el peculiar carácter moral y pedagógico que allí le fue otorgado y que no tuvo en otros pueblos en los que floreció con tanta o más profundidad que en Grecia» («El amor dorio», art. cit., p. 66). G. M. A. GRUBE, comentando el discurso de Pausanias en El Banquete, añade: «La única forma de asociarse digna es aquella que tiene por objeto la perfección moral. La asociación física está libre de vergüenza cuando -y sólo cuando- busca educar al amado en la sabiduría y el valor», El pensamiento de Platón, Madrid, Ed. Gredos, 1973, p. 157.

22. Cf. José S. LASSO DE LA VEGA, «El eros pedagógico de Platón», art. cit., págs. 124-125.

23. Ibid. p. 113.

24. Así se señala específicamente en Heraclés: «intentan oponer a la dinámica disoluta de la vida una estabilidad ideals. La influencia de Heráclito en el pensamiento gilalbertiano, si bien presente en toda su obra, aflora como objeto de reflexión específica en Concierto en mi menor, op. cit., pp. 78-92. 
Y en Heraclés: «Porque la estética es un camino de la verdad, o sea, una experiencia del conocimiento (...) es la actitud pensante... de los que fueron impresionados, implacablemente, por la hermosura de la Creación» (H. págs. 205-6) 25 $^{25}$.

Pero si todo lo vital es transitorio, no lo es menos el amor. Y no sólo por el deterioro de la belleza física del amado, sino como característica esencial de su cumplimiento. De ahí la ya antigua vinculación amor/muerte, en un intento de eternizar la imagen amada. Si en todo amor, nos dice Gil-Albert, se cumple la divisa de la fugacidad, en la modalidad homosexual lo hace de una manera especialmente inequívoca. Produciéndose al margen de la sociedad, no se ve desfigurada por sus convencionalismos, ni se confunde con la convivencia o la costumbre, pero esta autenticidad que suele caracterizar la relación homosexual, no disfrazada con otros atributos que los del amor, la deja mucho más expuesta al rigor de las mutaciones. A través de las distintas historias de Valentin, Razonamiento inagotable y Los Arcángeles veremos que el aprendizaje que conduce a estos seres a vislumbrar el sentido último de su destino, no se detiene ni en la aceptación de la propia naturaleza, ni en la entrega amorosa a otro ser, sino que, avanzando más, es preciso profundizar en «toda la inestabilidad» que conlleva el amor «en su trayectoria natural». Advertiremos también cómo se separan aquí el arte y la vida, antes vinculados, y cómo, en último término, la imagen misma de Eros será superada -sin que ello implique una renuncia al amor o al placer- en favor de una finalidad más amplia y más sublime para el hombre: la atención a todo lo viviente y a sus enigmas ${ }^{26}$.

\section{LA HOMOSEXUALIDAD EN LAS OBRAS DE FICCION}

La temática amorosa-homosexual es tratada en estas obras desde puntos de vista y preocupaciones diferentes. Siendo en Valentín y Los Arcángeles un problema circunscrito a la conflictividad interna de los personajes-narradores, en el marco de una literatura de carácter confesional, adquiere en Razonamiento inagotable una proyección más bien social, y el papel de Diego, responsable también del relato, queda reducido en este punto al de espectador comprometido, o mejor, al de mentor y consejero. Valentín se acoge al modelo de la autobiografía ficticia de índole agustiniana en la que el narrador comienza el relato de su vida a partir de una revelación ${ }^{27}$. En el caso de Richard, actor y empresario teatral en la Inglaterra de Shakespeare ${ }^{28}$, la «impia» revelación arranca

25. En Breviarium Vitae, Alcoy (Caja de Ahorros de Alicante y Murcia, 1979), Gil-Albert llega a decir: «Tener como moral una estética no es, como se cree, inmoral, sino sentirse gobernado por una moral, tan exigente, si se quiere, pero más ecuánime, de cuya participación no han sido excluidos los sentidos» (Vol. I, p. 287).

26. Para el tema de la sublimación del amor en el pensamiento socrático/platónico, sólo posible en quien «ama a los muchachos rectamente», cf. GRUBE, El pensamiento de Platón, op. cit., pp. 165-168 y José FERRATER MORA, Diccionario de Filosofia, I, Madrid, Alianza Editorial, 1979 , pp. 123-124.

27. Jean Starobinski señala que «ll n'y aurait pas eu motif sufissant pour une autobiographie, s'il n'était intervenu, dans l'existence antérieure, une modification, une transformation, radicale; conversion, entrée dans une nouvelle vie, operation de la Grâce. Si le changement n'avait pas affecté l'existence du narrateur, il lui aurait suffi de se peindre lui-même une fois pur toutes», «Le style de la autobiographie», Poétique, n. ${ }^{\circ} 4,1970$, p. 261.

28. Varios autores, y entre ellos GIL DE BIEDMA, advierten que en el homenaje que Gil-Albert dedica a Shakespeare con esta obra, puede latir la idea de la atribución de los primeros sonetos del escritor inglés a un amor homosexual («Juan Gil-Albert, entre la meditación y el homenaje», epílogo a Valentín, op. cit, pp. 175 y 183). Sobre el problema de las especulaciones en torno a la identidad del joven al que irían dedicados los primeros 126 sonetos, y cuyas iniciales serían Mr. W. H., cf., S.C. SEN GUPTA, A Shakespeare Manual, Calcutta, Oxford University Press, 1982, pp. 159-162. 
de su crimen, al descubrir y aceptar su amor por el joven Valentín, al que había dado muerte durante la representación en escena de Otelo. En el contexto de la ficción, su relato se presenta como una confesión antes de morir, válida «para ambas justicias, la terrenal y la eterna» (V. pág. 26). Despliega una larga mirada introspectiva sobre su existencia pasada, como si la «revelación» precisase después de un conocimiento racionalizador que implique todos los pormenores de la actuación anterior, pero contemplados ya a la luz del descubrimiento, que es punto de partida y de llegada. Como personaje trágico, Richard narra los hechos que le llevaron, de forma inevitable, al cumplimiento de su destino; nos habla de sus orígenes, de los años de formación que determinaron el desarrollo de su personalidad, simbólicamente dualista, atraída tanto por el recogimiento del estudio, como por la vida, a través de su trabajo como actor ${ }^{29}$. El conocimiento de Valentín abre una etapa de amistad espiritual y pedagógica que sufre su primer trastorno, para Richard, durante un viaje por Italia en el que descubre la belleza del cuerpo de su amigo: «Ocurrió... lo imprevisto; ahora sé que lo inevitable», la revelación de Eros. Desde entonces la vida de Richard queda determinada por la resistencia que se impone para no reconocer su pasión, ayudado por la idealización estética que le ofrece el arte. Pero, como dijera Ausias March, «Amor es dat coneixe pels efects» y la maduración que lleva a Valentín hacia la mujer y a un progresivo distanciamiento del núcleo amistoso, hace caer a Richard en la ofuscación de los celos, intensa degradación del personaje -tanto más compleja por cuanto no se reconoce su origen-, que sólo concluye al matar a Valentín /Desdémona, suplantado por la personalidad de Otelo.

La precisa labor indagadora de Richard -casi policíaca- supone una constante reestructuración de los episodios vitales, y el lector, de la mano del personaje, se enfrenta a un enigma, cuya solución se produce en varias etapas. Pero, ¿dónde radica el criterio de verdad? Sin duda, en que Richard es un condenado a muerte, pero más aún en el interés del propio personaje por descubrir la verdad y envolver su experiencia en el halo del conocimiento. Y en el dominio del arte, habría que añadir. El crimen de Richard, llevado por su deseo de eternizar la imagen de Valentín, le ha hecho penetrar en el verdadero saber, aquél que, en palabras de Nietzsche, no viene de la reflexión, sino de «la mirada que ha penetrado en la horrenda verdad», y desde ahí el único camino que queda abierto es el del arte, capaz de modificar «lo espantoso o absurdo de la existencia convirtiéndolos en representaciones con las que se puede vivir» ${ }^{30}$. El relato de Richard es entonces algo más que una confesión, es un modo de dar significación duradera a sus actos y a su vida, de dar forma definitiva al apresamiento eterno del amor que buscó en su crimen. Y ésta es la forma del arte.

Los Arcángeles posee una estructura menos unitaria. El tono confesional e introspectivo reaparecen, sobre todo, en la primera parte, así como la necesidad de esclarecer un presente oscuro y confuso, como justificación de la escritura. Del estado de crisis en que lo ha sumido un desengaño amoroso intenta salir Claudio durante su estancia en un monasterio, recurriendo a un método de análisis similar al empleado por Richard, y a través de un «examen de conciencia»" ${ }^{31}$. Pero la «transformación» del personaje no es un dato previo, sino que se produce a los ojos del lector, como acontecimiento simultáneo

29. Como muy bien señala José Luis GARCIA MARTIN, «Tal dualismo simbólico... no se reduce a la novela que comentamos, sino que abarca el sistema total de la obra de Gil-Albert», «Juan Gil-Albert, novelista. Notas sobre «Valentín», Calle del Aire, revista cit. p. 283.

30. Friedrich NIETZSCHE, El nacimiento de la tragedia, Madrid, Alianza, 1976, pp. 78-79.

31. La proximidad que Gil-Albert muestra, en algunas de sus obras, con las autobiografías religiosas -San Agustín o Santa Teresa- no se reduce sólo a la acuciante preocupación por la ejemplaridad, que sería además un medio de restaurar una forma de lectura, sino también al método empleado para llegar al conocimiento del «yo». CF. Eugène VANCE, «Le moi comme langage: Saint Agustin et l'aubiographie», Poétique, París, n. ${ }^{\circ} 14,1973$. 
al momento de la escritura, y reforzado por el encuentro de Claudio con el joven «arcángel» Miguel, que le restituye en su estabilidad amorosa. La obra se aproxima, en este sentido, a la estructura del diario, aunque no haya una sucesión de fechas, salvo en el caso de la última parte, donde, bajo el título «Bloc-22», se recogen una serie de reflexiones de temática variada, que adoptan a veces la modalidad del aforismo tan cara al autor. Si atendemos a la designación que da Gil-Albert a Los Arcángeles, se trata de una parábola, un recorrido alegórico a través de tres modos de ralación amorosa homosexual, construidos sobre tres anécdotas. Las reflexiones que se desencadenan modelarán intelectivamente el aprendizaje simbólico de Claudio consistente en una comprensión de los efectos del amor que requiere la racionalización del sentimiento. Un aspecto importante de la obra es la inserción del tema en la historia de la cultura. Claudio pone en estrecha relación sus inquietudes vitales y su proceder con aquellas voces del pasado que hablaron del amor viril, o simplemente, del amor: Teognis de Megara, Dante, Aristóteles, Platón, los místicos, con cuyas aportaciones el «relato» avanza en una línea específica de pensamiento: la sublimación del amor. Pero ello no resta a la obra ni un ápice de su «atrevimiento», ni mitiga la amplitud con la que Gil-Albert se decide a tratar del «amor socrático», al incluir también el encuentro sexual -algo que no tiene cabida en los otros textos- entre Claudio y Miguel, perfectamente compatible en la cosmovisión gilalbertiana con la idea espiritual del fenómeno amoroso.

En Razonamiento inagotable el tema del homoerotismo no cobra preeminencia hasta la última parte de la obra. Antes de ponernos en contacto con los personajes en cuyo círculo se desenvuelve la existencia de Delfín, joven de dieciocho años que, tempranamente, asumió su distintiva naturaleza homosexual, Diego dirige su relato hacia su propia vida, tras su regreso a España del exilio; reflexiona extensamente sobre estética pictórica, y evoca los años de amistad juvenil con Andrea y Santiago, antes de reencontrarse con ellos y con su incomprensión a la hora de aceptar plenamente el modo de ser de su hijo Delfín. Abordando esta problemática entre otras y colocando a los seres de «excepción»-Diego, Delfín y Jaime- en medio de un número inusitado de personajes, no parece sino que Gil-Albert ha querido llenar ese vacio existente en la mayor parte de los novelistas al que alude en su obra Viscontiniana ${ }^{32}$. Vacío en la presentación del homosexual, ya no como una rareza social que requiere atención específica, sino «como personaje accesorio o entrelazado con los demás», algo que, para Gil-Albert logra realizar Thomas Mann en La montaña mágica. En Razonamiento inagotable, sin embargo, la defensa que se hace del fenómeno y la insistencia en su naturalidad, sin olvidar la posición pedagógica que ejerce Diego, adquiere tal carácter de enunciación de principios, que en ningún momento puede parecer un simple encuentro del escritor con la realidad multiforme que observa.

\section{ESTETICA Y PEDAGOGIA}

La personalidad psicológica y moral de Claudio, Richard y Diego presenta una serie de coincidencias que vienen a resumir con gran coherencia las características anímicas que Gil-Albert concedía al temperamento homosexual en Heraclés. Son personajes altamente idealizados, pero no perfectos, sometidos, más bien, a que se resquebraje el equilibrio en el que desean ampararse como consecuencia de los imprevistos vitales. La perfección no es sino la búsqueda realizada en la escritura: una demanda permanente de autoconocimiento. 
La primera coincidencia entre los tres personajes es su relación con distintos dominios del arte. Richard es actor de teatro y su cultura se ha enriquecido, además, con la educación recibida en el claustro, donde se puso en contacto con el «seductor clima de los libros»; Claudio es un escritor con amplios conocimientos, y Diego, siendo pintor, se siente atraído también por los poetas, los filósofos y hasta los científicos. Lo significativo, sin embargo, es que para todos ellos el arte sea, como se dice en Heraclés, «una manera, específica, de vivir... no un oficio incorporado, sino una tendencia aprehendida: una vocación» (H. pág. 182). Tanto Diego como Richard se sienten distintivamente sellados para el trabajo que realizan: «¿Es acaso un oficio? -se pregunta Richard- ¿No parece más que un deber, una gracia, una lujosidad?» (V. pág. 30) ${ }^{33}$. Esta disposición acaba traspasando la esfera del arte; como en la historia de Dorian Gray de Oscar Wilde, la imagen del mundo se contempla como un «totalidad estética» ${ }^{34}$. «Lo estético-dice Claudio- es, para mí, un sentir y una necesidad, algo así como una dignificación de la vida, sin la cual ésta pierde forma» (L.A. pág. 44). Cuando la actitud estética es una forma de vivir, indudablemente, se está ya en el camino de una moral particular, la estética, que guía las actuaciones de estos personajes.

El caso de Richard, sin embargo, ejemplifica muy bien el hecho de que, aunque las realidades del arte puedan tener tanta potencia como las de la vida -si no más-, el arte nunca redime de la vida ${ }^{35}$. Así se expresa en Crónica General: «el arte no es un sustitutivo de la vida, sino una rivalidad; algo que está en pugna, en lucha cerrada con ella, en apretado abrazo» (C.G. pág. 74). Para Richard los componentes vitales que encuentra en su trabajo de actor parecen colmar, en principio, sus apetencias y el desarrollo de su integridad humana, hasta que el tropiezo con el amor le muestre el lado ignorado de su condición.

Entre otros muchos paralelismos existentes en la conducta y el pensamiento de estos personajes -que tanto recuerdan, por otro lado, a la propia personalidad literaria de Gil-Albert-, no podemos pasar por alto el verdadero sentido pedagógico que tenía la relación homosexual en la tradición griega, relación entre un hombre adulto (erasta) y un adolescente (eromeno), basada en un deseo de seducir, correspondido por el amado con un sentimiento de admiración y un ansia de alcanzar su altura espiritual. Como sentimiento complementario se desarrollaba en el amante una vocación pedagógica y se constituía en maestro de su amigo ${ }^{36}$. Modelos efectivos de este método de enseñanza cifrado en la entrega de sí mismo y en la voluntad de ennoblecimiento serán las relaciones «maestro-discípulo» que se entablan entre Richard-Valentín, Claudio-Miguel y Diego-Delfin. Como dijera el poeta Teognis a su amado Cirno: «Como un padre a su

33. Hans Mayer describe el mundo presentado en Los monederos falsos -existente también en otras «novelas homosexuales»- como un mundo parasitario, que a veces se ofrece como fenómeno estético (op. cit., p. 246). Quizá esto conviniera a Claudio, al decir al joven Miguel que «no tenía profesión ninguna. Que a mí, también, como a él, lo que me gustaba era vivir sin nada y, casi, de la nada; lo que la gente llama perder el tiempo» (L.A., p. 54). Se trata, precisamente, de disfrutar de ese «ocio virgiliano», que Gil-Albert anhela también para él, según cuenta en Crónica General, op. cit., pp. 317-318.

34. Sobre el papel que Oscar Wilde desempeñó en la formación de Gil-Albert, al revelarle «la vida humana como obra de arte», cf. también Crónica General, op. cit., p. 511.

35 Véase Jaime GIL DE BIEDMA, art. cit., pp. 179-182.

36. «Tal sentimiento -explica Henri-Irénée MARROU- se aclara a la luz de un análisis freudiano: evidentemente, el instinto normal de la generación, el deseo apasionado de perpetuarse, se deriva y se desborda al plano pedagógico. La educación del mayor aparece como un sucedáneo, un «ersatz» irrisorio del alumbramiento: «El objeto del amor (entiéndase, pederástico) es procrear y engendrar en la Belleza», Historia de la educación en la Antigüedad, Buenos Aires, Ed. Universitaria, 1976, p. 36. Por su parte, Bernard SERGENT llama la atención sobre el carácter iniciático que conllevaba esta relación en el rito de la homosexualidad, La homosexualidad en la mitología griega, Barcelona, Ed. Alta Fulla, 1986, pp. 277-283. 
hijo, yo te daré buenos consejos/ Tú recíbelos en tu espíritu y en tu corazón». Gil-Albert recuerda esto en Heraclés:

En toda pareja amorosa homosexual, sobreviene de algún modo, la emoción, todo lo periclitada que se quiera, del diálogo platónico. Una pedagogía particular, vivaz, extrañamente interesada, mantiene en vilo, y en constante zozobra, el pábulo de los apetitos docentes: el afán de conocer las cosas, la curiosidad por lo vivo, la atracción de lo ignoto... Son las etapas inevitables del humanismo en su progresión creciente. Y que, hacen imprescindible, en la constitución de la pareja socrática, al que pregunta, y al que responde. Aquel que sabe y el que quiere saber... (H. págs. 208-209).

La conducción que el elemento adulto ejerce sobre el joven es, pues, de índole socrática y, ejercida en libertad (Cf. H. pág. 200), no impone ni adoctrina; su propósito es sacar a la luz lo que de modo intuitivo y confuso residía ya oculto en el alma amada. El mayor elogio que pueden recibir quienes laboran en este sentido es el que Miguel dispensa a Claudio: "Me gusta estar contigo..., se ve más claro» (L.A. pág. 66). La conversación y la vida en común son el terreno en el que se desenvuelve la relación pasional. Las extensas charlas de Diego con Delfín, aunque entre ambos no exista el vínculo del amor, sino la afinidad espiritual, o la estrecha camaradería de Richard con Valentín, que aquel imaginaba imperecedera. «Podríamos resumir diciendo -se explica en Heraclés- que el alumno sale de las manos del homosexual no convertido en un ingeniero, pero sí en un hombre. En el sentido de su integridad, de su soledad» (H. pág. 209). Veremos, sin embargo, a través de Razonamiento inagotable, que la vida vuelve a interferirse en los deseos del hombre y que esta transmisión del saber por la palabra (oral) no siempre podrá llevarse a término. Los consejos, las experiencias y las advertencias de un hombre no podrán alzarse en sustitutos de la propia experimentación, tantas veces dolorosa, a través de la vida. La herencia que recibe Gil-Albert de los caminos recorridos por los místicos se ofrece aquí de forma muy clara.

Las coincidencias que hemos registrado entre el carácter de los personajes no impiden que los conflictos amorosos a los que se enfrentan tengan, no sólo causas diferentes, sino un modo diverso de manifestarse. Precisamente a partir de los puntos que los unen -a la hora, por ejemplo, de enfocar la psicología y la metafísica del amor-, creemos poder descubrir las etapas sucesivas que el homosexual debe ir superando en el cumplimiento de su destino, según se describían en Heraclés.

\section{EL RECHAZO TRAGICO DE RICHARD: FILOSOFIA DEL AMOR}

El repudio de la pasión amorosa homosexual se produce sólo en el caso de Richard. Las consecuencias de esta «humillación del ser» no afectarán tanto a un sufrimiento especial de los efectos del amor -existente también en los otros personajescomo a la imposibilidad de superarlos racionalmente. Pero, como ha señalado Gil de Biedma, el planteamiento no tiene nada de convencional ${ }^{37}$. Primeramente, porque la resistencia del personaje a ceder a su inclinación por Valentín no se debe a los prejuicios de una moral tradicional y, Richard, en su papel del hombre que confiesa sus faltas, no deja de repetirlo:

Este fingimiento mío no era el del vulgar simulador que se impone, con respecto al mundo que le rodea, una conducta que lo ha de favorecer; tampoco, creo yo, era, propiamente, de raíz religiosa ni se apreciaba en mí esa lucha áspera con el pecado (...) Mi lucha era de otra índole... era, más bien, la defensa de una adquisición que yo consideraba distinguida: saberme distinto de los otros. (V. pág. 83). 
La posición de Richard supera el marco de la aceptación de la homosexualidad, situándose, inicialmente, en un rechazo de las debilidades del amor en sí mismas. Esto implica la mutilación del «hombre integral» (en el que se armonicen la razón, los sentimientos y las pasiones) y el alejamiento de la vida, ya que el amor es una de sus manifestaciones más preciosas y excitantes ${ }^{38}$. No creemos, sin embargo, a diferencia de lo que opina Gil de Biedma ${ }^{39}$, que el error radique en que la «magia del arte» que envuelve al personaje sea una "realidad suficiente», hasta que se entromete la vida, pues el arte no es algo secundario, para Gil-Albert, sino distinto de la vida. Si algo precipita a Richard hacia su trágico destino es el hecho de haber construido su ideal «excepcionalidad» sin haber contado con todos los elementos de la realidad que lo constituyen y, al mismo tiempo, acogiéndose a un proceder estético fundamentado en bases falsas.

El equilibrio y una alta dignidad ética son rasgos favorecedores de su carácter, mas, como indica Emil Staiger, al analizar las condiciones de la tragedia: «Si lo que ha pasado por alto (el héroe) se abre camino haciendo valer sus derechos, entonces la acción dramática es trágica» ${ }^{40}$. Richard, prevenido en todo, ha prescindido en su camino de su capacidad de amar:

Claro que el amor -dirá Gil-Albert en Heraclés- se burla casi siempre de sus férvidos detractores y, benévolo y risueño, al fin y al cabo, soporta el temporal, se cuela por alguna rendija entre los intersticios del alma infiel, y acaba personificándolo todo en los dones ocultos de la divinidad... (H. pág. 173).

Este es el papel que desempeña la juventud y la «divina» belleza de Valentín. Ante el nuevo estado de espíritu, y dado el temperamento artístico de Richard, la idealización por medio del arte se convierte en refugio y negación de la realidad. Ahora bien, este impulso «estético» se explica también por las características que se otorgan a la manifestación del fenómeno amoroso. La cosmovisión gilalbertiana hace gala, en este punto, de un completo misticismo neoplatónico al convertir el amor en una «experiencia metafísica» ${ }^{41} \mathrm{o}$, más exactamente, por el componente idolátrico que conserva, reconocemos de nuevo a Platón, ya que el ser bello se revela, más que como «esplendor de la luz divina», propiamente como un «semidiós». Si amar, como dice Richard, «es centrar en alguien la atracción del cosmos» (V. pág. 100) ${ }^{42}$, se aproxima a la «comunión» que, con una perspectiva más bien romántica, se produce, según Gil-Albert, en la contemplación estética, y a ese sentimiento de «fusión con el Todo» que puede experimentarse, tanto en el contacto con lo natural, escuchando el «clamor profundo» del universo, en el silencio reinante (cf. R.I., pág. 76), como ante la exaltación del amor. Richard se halla en un estado anterior a cualquier posible racionalización de su sentir: «... era aquel cuerpo...

38. Aunque esto sea así, no estamos de acuerdo con Gil de Biedma, cuando señala que «la naturaleza homosexual de los sentimientos de Richard... son, desde el punto de vista del significado de la obra, factores concomitantes, secundarios» Ibid., p. 183, puesto que, como hemos visto, el amor viril tiene unas características sin las cuales no se entenderían muchas de las actuaciones de Richard.

39. Cf. art. cit., p. 181. La alegría final del personaje, una vez cometido el crimen, vuelve a constituir una percepción estética de lo real, sólo que sobre fundamentos verdaderos. $192-3$.

40. Emil STAIGER, Conceptos fundamentales de poética, Madrid, Ed. Rialp, 1966, págs.

41. Cf. Edwin PANOFSKY, Renacimiento y renacimientos en el arte occidental, Madrid, Alianza, 1975, pp. 185-195.

42. Definición que vuelve a aparecer en idénticos términos en Los Arcángeles, p. 103 y en Cantos rodados, pág. 43. Sin duda, a través de la estética modernista que cultivó Gil-Albert en sus años juveniles, asimiló muchos elementos de una cosmología pitagórica familiar también a los poetas renacentistas. Cf. Allen W. PHILLIPS, Temas del Modernismo hispánico y otros estudios, Madrid, Gredos, 1974, pp. 53-55, y, especialmente, Francisco RICO, El pequeño mundo del hombre, Madrid, Castalia, 1970. 
el que, mis ojos... hacían suyo, con una apropiación tan vehemente que parecía anular en su posesión al mismo poseedor» porque «no se trataba de una compenetración sino... de una sustitución» (V. pág. 72). Anhelo místico de disolverse en el amado y de unión completa con él, sólo posible -diría León Hebreo-para las almas, pero no para los cuerpos $^{43}$. Sólo la muerte le ha deparado a Richard la posibilidad de unirse a Valentín en la «celeste morada» que imagina en el prólogo de su relato.

Pero en el dominio de la vida, Diego expone, al indagar sobre su propio caso, en qué medida lo real resulta «desacorde» con la Idea:

El ser amado aparece... aureolado con la investidura de un semidiós. Pero como aún en los casos más excelsos no lo es, la pugna entre la realidad y la idea se agravan y de ahí se deducen estados críticos e inclementes para el ser adorado y para el adorador: divinidad y sacerdote de un culto viejo y, como éste, sin fin (R.I., pág. 48).

Es la propia «hybris» de Richard la que lo lleva al crimen, al creerse superior a los demás en algo en que no podía serlo, y haciéndose, diríamos, inhumano. Lo trágico de su ineludible destino es la consecuencia de haber luchado «con encarnizamiento por vencer la pasión, por vencerla no por padecerla, y en esto podria residir, en vista del fatal desenlace que he presenciado, mi error» (V. pág. 101), es decir, de haberse negado a otro destino que también le correspondía: el de su naturaleza pasional y homoerótica. Dejándose llevar por el «engaño del arte», se enfrenta con el ineludible problema del tiempo que amenaza con la corrupción de Valentín ${ }^{44}$. La Belleza sólo es incorrupta en la obra artística, y de ahi la equivocación de Richard, su verdadero pecado, la hamartía, más próximo a la moral pagana de la tragedia, que a los principios morales del Cristianismo.

Desde un punto de vista ético dos son los problemas que se entrelazan en la obra, permitiendo su vinculación con los otros textos: el de la aceptación de la pasión amorosa en cualquiera de las formas que adopte, y el de las condiciones de la vivencia (homosexual) del amor. Con relación al primer tema, Claudio y Richard aparecen como personajes antitéticos, cuando menos en el grado de conocimiento que tienen de sí mismos. El actor teatral aparece convencido inicialmente de que «por no sé qué protección benévola, o quizás por mi mayor severidad emocional, estaba llamado a librarme de esa esclavitud a la que llaman amor...» (V. pág. 44).

En tanto que Claudio califica de un modo muy distinto su actitud ante el amor:

Desde siempre lo he seguido porque me eligió entre sus seguidores, me eligió para seguirle, y equivocado, oí su llamada y he puesto en su persecución, inagotable, lo que otros en fundir un imperio...» (L.A., pág. 14).

\section{EL «CUMPLIMIENTO» DEL AMOR COMO SUPERACION DEL TIEMPO}

Lo que en Richard es rechazo, en Claudio se convierte en una religión y, prevenido sobre la naturaleza este sentimiento, conoce la «temeridad de su cruzada» por la especial

43. CF. Alexander A. PARKER, La filosofía del amor en la literatura española (1480-1680), Madrid, Cátedra, 1986, pp. 96-106. En Heraclés dibuja muy bien Gil-Albert la importancia que tiene para él «la simiente erótica del misticismo» y el interés que despierta en el homosexual el léxico empleado por los místicos, pues «con aquellos vocablos encendidos, se corteja... un amor, como si dijéramos, extrarradial» (H. pág. 50). Cf. Daniel de PABLO, Amor y conocimiento en la vida mística, Madrid, Universidad de Salamanca, 1979, pp. 83-90.

44. Así lo indica Luisa Capecchi: «Pero lo creado exige también su conservación y es, éste, el tercer momento del Tratado. La necesidad de salvar la belleza de la propia corrupción... Richard no sabe construir algo eterno, incorruptible; por eso es necesaria la muerte...», art. cit., p. 40. 
virulencia de sus efectos. Es consciente además de su distinción y no ejerce violencia alguna sobre la naturaleza que le ha correspondido. De ahí su desconcierto ante su estado, verdadera «noche oscura del alma»:

Sabido esto, ¿cómo a estas alturas de mi caso propio, de mi experiencia personal puedo yacer vencido por una vicisitud que conozco de antiguo en trances anteriores, y que debiera, por tanto haber consumido ya la virulencia que deprime mi alma...? (L.A., pág. 14).

Llama la atención el enorme contraste que existe entre el crimen de Richard, que origina su relato, y la insignificante anécdota que se presenta como única causa del derrumbamiento de Claudio: el episodio del regalo de una pulsera a Gabriel -con la que Claudio sella, de algún modo, su vínculo- y el episodio en que sorprende a éste entregándosela a una amiga. La falta de trascendencia sólo es aparente si tenemos en cuenta la importancia que Gil-Albert, al igual que Montaigne, concede a lo anecdótico en toda su obra. Y también Claudio:

Fijémonos bien en esto: Hay siempre una anécdota inverosímil que, al irrumpir en nuestro medio con presencia inesperada, desarticula, frenética, en unos segundos, la labor paciente de un tiempo que nos parecía haber salido victorioso de la caducidad inherente a cualquier manifestación de nuestra vida. (L.A., p. 18).

Ese pequeño percance enfrenta directamente al personaje con la caducidad del amor y su indagación discursiva aparece como el intento de superar esa realidad incontestable, que logrará no sólo con ayuda del raciocinio, sino con la participación de lo vital. Claudio alude a su tendencia a ser constante en el amor:

Pero la vida me ha acostumbrado a aceptar, debo decir que me ha impuesto, otro punto de vista, seguramente más real por más acorde con las mutaciones constantes del mundo, con la constancia, diríamos, de su constante inconstancia. (L.A., págs. 15-16)

Este personaje asiente ante lo que Richard se negaba a ver: que «el amor es fugaz, que debe serlo». ¿Cuál es entonces la causa del desequilibrio y del sufrimiento? Claudio la considera más «ideológica» que humana: «en mí... la idea actúa como configuración plástica de un deseo, troquela, perentoriamente, con un sentido de sublimidad, el simple acontecer, sin premeditación del hecho a secas» (L.A., pág. 22). Nuevamente tropezamos con el proceder del artista que quiere convertir su vida en obra de arte. Pero la pretensión idealizadora de Claudio no es idéntica a la de Richard, puesto que aquél no busca eternizar las cosas sino darles significación o, como diría Gil-Albert, transformar las anécdotas en acontecimientos. El «anhelo del Ser» que persigue Claudio, y que es compartido por el autor, se entiende como cumplimiento de las cosas antes de su desaparición. Quizás esto explique también la tendencia del escritor alicantino a componer sus obras como una «recreación» de hechos ya ocurridos, dirigiendo la mirada hacia el pasado y permitiendo que el conocimiento del futuro dibuje el acontecer como un todo coherente, cuando no como los pasos de un destino significativo.

El sentido de este deseo (o exigencia) de que «las cosas lleguen a ser lo que se proponían» se puede captar mejor cuando Claudio lo aplica a la misma muerte, también sometida al cumplimiento, 
Esta razonable proposición humana que justifica la rebelión del hombre contra una nauraleza más que injusta, incomprensible, puede aplicarse a la aventura amorosa de Claudio, al haberse malogrado en su relación ese «anhelo del ser»: «Si Gabriel se hubiera desprendido de mí siendo, siendo lo que creía que era «animas dimidium meae», la brecha dejada abierta en su emancipación se hubiera restañado» (L.A., pág. 17). Sólo a través del amor «realizado» puede el hombre «inmortalizarse» por «haber integrado, una vez al menos, y todo lo casualmente que se quiera, la realidad» (L.A., pág. 17). Pero para ello se hace necesaria la «comunión» entre dos seres, la coincidencia y la correspondencia, a fin de que el amor sea algo más que un «fantasma» o una proyección «más allá de la caverna» ${ }^{45}$. Gabriel le ha traicionado, de algún modo, ha roto esa «comunión» permitiendo, además, que se inmiscuya un elemento extraño en la relación viril; se ha mostrado como un alma indigna, innoble, en la que no pueden germinar las enseñanzas del erasta. El fracaso de la «Idea» rectora del encuentro amoroso sume al personaje en un estado del que no sanará más que por el sufrimiento. La consideración «positiva» del dolor, como paso previo para la ascensión hacia Dios, era un elemento fundamental en las doctrinas místicas. Fiel a este legado, Gil-Albert ha comprendido el valor moral del sufrimiento y no deja de introducir en él a sus personajes como medio de alcanzar la «purificación» y la serenidad que les depara el conocimiento más auténtico de sí mismos. Las imágenes y el léxico empleados por el autor para describir estas situaciones confirman esta vinculación con los escritores místicos, aunque también resuene, como antecedente más lejano, el concepto pitagórico del hombre como microcosmos ${ }^{46}$. Claudio, Richard o Diego «descienden» a las profundidades de su ser para arrancarle su verdad, y Richard escribe desde el «agujero informe» que es su prisión y su alma, muy similar a la estancia conventual de Claudio al comienzo de su relato. En el transcurso de las reflexiones de este último personaje veremos clarificarse un problema, ya planteado en la historia de Richard, pero que cobra todo su relieve en Los Arcángeles, en tanto que aparece como algo resuelto y superado en Razonamiento inagotable.

\section{LA ACEPTACION ARMONICA DE LA SOLEDAD}

El protagonista de Valentín enuncia ya uno de los principios claves de la actitud que el hombre, según Gil-Albert, debe tomar ante el amor después de comprender que «el amor es un punto de partida, pero nunca un lugar de arribo» (V. pág. 100). De forma similar se había formulado en Heraclés: «El amor, y su felicidad es, más que la meta de la vida, su excitante máximo... lo cierto es que no colma todos los aspectos de la apetencia humana de vivir» (H. pág. 198). Pero el alcance de esta evidencia no se aprecia bien en el caso de Richard al mezclarse con su rechazo del amor homosexual. Claudio demuestra cómo tampoco aquellos que se acomodan a su naturaleza se ven libres de la idolatría concentrada en un solo ser, ni de la virulencia característica del amor viril:

Cuando el amor es un accidente la turba pasa; pero cuando se establece en medio de una vida como la pared medianera que comunica lo particular con el todo, que hace de pantalla medianera entre lo que vemos y lo que aspiramos saber, entonces, un imperceptible movimiento sísmico sirve para que, aquella pared en la

45. Ibid. p. 39.

46. Es cierto que, como dice Leopoldo AZANCOT, «Grandeza de Juan Gil-Albert», La Estafeta literaria, 15 de junio de 1974, pp. 1745-6, las referencias a Pitágoras están ausentes en la obra de Gil-Albert, pero no el pitagorismo que, dado su interés por el mundo clásico debería conocer aunque fuese superficialmente. 
que se apoya ilusoriamente la construcción de nuestra confianza, se tambalee... (L.A. pág. 15)

Diego es, entre estos personajes, el más firme y maduro. Su conflicto se remonta al pasado, pero el espacio que dedica en su relato al momento en que se le aparece su «estrella cenital»-el descubrimiento del amor- es tan breve, y cuenta con tan escasos detalles, que puede parecer algo marginal, destinado, eso sí, a la caracterización moral y emocional del personaje. En realidad, esta cuestión se engarza con otro problema que afecta también al homosexual en el marco de la amistad. El abandono en que se siente al iniciar Andrea y Santiago sus relaciones amorosas -a espaldas suyas-, le hace cobrar conciencia de la ineludible soledad que le impone el hecho de que su «acometividad» estuviera requerida, «con discriminación tajante, por otro objeto amoroso» (R.I., pág. 35). Sus reflexiones sobre ambos temas complementarios son las de quien ha recorrido un largo camino, y no podemos dejar de verlas sino como un compendio de la estructura parabólica de Los Arcángeles. Brevemente refiere su evolución desde el tiempo en que el amor penetrase en él «con violento impulso sensacional, que quién sabe si no está tan alejado, como podría parecer, de ciertas actitudes místicas», hasta que

(...) se fuera aposentando un sentimiento que yo llamaría socrático, la comprensión amorosa, y en cuyo clima se recogen si no los resultados exultantes, sí los más sazonados (R.I., pág. 48)

Ha superado la «vehemencia física», alcanzando esa «racionalización del sentimiento» que recomendase Platón por boca de Sócrates. Se convierte así en el guía de Delfín que acaba siendo su propia proyección y reflejo. Casi diríamos que en Razonamiento inagotable lo que se plasma es la antigua idea del eterno retorno, pues el joven al que quiere conducir y prevenir se quedará justo al comienzo de ese camino que ya ha transitado Diego. Su historia amorosa, con la muerte del ser amado, inaugura un ciclo que se repite en Delfín, cuando éste deba sobreponerse en solitario a la trágica muerte de su amigo Jaime. Este abandono en que queda el personaje no es casual. ¿Es posible enseñar el camino de la virtud?, se preguntaban los clásicos. Para Gil-Albert, sólo en parte $y$, como decíamos en otro lugar, sin sustituir la propia experimentación. Así lo expone Diego, al explicar su indiferencia ante las advertencias maternas, que también recibe Richard:

Eso que se llama el instinto materno podría ir preservándonos, si obedeciéramos sus alertas, ante los peligros... pero, entonces, ¿cómo fundirnos al fuego de la experiencia, cómo templar nuestro carácter, pasar, como quien dice, de hombre a dios? (R.I., pág. 36)

Los Arcángeles, estructurada en dos etapas espaciales distintas, la estancia de Claudio en el convento y su salida al mundo, también describe la evolución del personaje. La visión desdichada del amor se materializa en las relaciones con el primer «Arcángel», Gabriel, cuando se halla preso en sus propias inclinaciones místicas (Cf. L.A., pág. 13) y siente el abatimiento de su soledad. Su recuperación procede, en un primer momento, del arte, de la poesía de Teognis, más concretamente, cuyas palabras le «rescatan de la anómala soledad oscura, de la soledad inquietante, me incorporan... al subsuelo de la historia humana» (L.A., pág. 25). La «comunión» con la obra artística, con un texto que le habla de su propio sentir homosexual, es un medio de salvación para un temperamento «idealizador», que recupera el Ser al hermanarse con otras voces del pasado. 
Pero, además, es preciso reconciliarse con la vida, y esto es lo que Miguel (el segundo «Arcángel», el que es "como Dios», se dice en el Libro de Daniel) viene a propiciar. Este encuentro se convierte en un ejemplo de algo realizado, aunque sea fugaz, y origina el descubrimiento de Claudio de que «el mundo no es, en última instancia, más que un valle de encuentros. O sea, que venimos a eso, a encontrarnos» (L.A., pág. 56). Son también momentos de comunión, y entre los más perfectos aparece ése, con Miguel, que conmociona «iluminándonos por dentro»; imprevisto y al margen de las relaciones corrientes.

Idea fundamental en el pensamiento de Gil-Albert es la de la plena soledad del hombre ${ }^{47}$. Eso sí, se sale de ella para recibir «a los que llegan» y que son una especie de «anunciaciones». El sentido del título de la obra se hace evidente. Arcangélicos son los jóvenes efebos, caracterizados todos ellos por su «ingravidez» -frente al peso que confiere al hombre adulto su espiritualidad-, por su belleza y por su «divinidad», pero también por el mensaje y la revelación que traen consigo -y que son ellos mismos-, en tanto que propician un estado amoroso, cuyos atributos no son otros que los descritos por los místicos: «enajenación» en la contemplación del ser amado, a través del que se revela el Todo, y «ensimismamiento» porque se está fundido con el Todo (Cf. L.A. págs. 59-60).

Desde el momento en que Claudio descubre que el amor no es la finalidad de la vida, ya puede seguir amando. Y ésta nos parece que es la función del último arcángel, Rafael, que representa la continuidad de la existencia, pero a la que se entrega el personaje desde su profunda transformación y entendimiento de hallarse ante algo pasajero. Se acerca a la vida desde su reconocida soledad primigenia. En ello instruye Diego a Delfín, sirviéndose de la historia de Orestes, cuyo sino es la soledad auténtica:

No la soledad del solitario, sino del que se sabe solo y, más aún, del que sabe, del que ve palpablemente, por lo que acaba de ocurrirle, que el hombre está solo (R.I., pág. 88)

Si en Heraclés se dice que «el fin del vivir homosexual es una consecución de la libertad soberana, una puesta en práctica de la soledad integral», aunque no sea de tipo ascético, sino estético, y admita incluso el amor carnal, este principio no queda reducido para Gil-Albert a las condiciones de la homosexualidad. Constituye una máxima de orden general que sólo ciertos seres se atreven a enfrentar directamente:

El hombre -se escribe en Cantos rodados- no alcanza su meta verdadera hasta que no llega a sentir lo absoluto de su soledad... El escalofrío que acompaña a esta especie de descubrimiento fatal, lo templa (C.R. pág. 125)

\section{Como para Unamuno templaba al hombre el pensamiento de la muerte}

Aunque desde un punto de vista ético las tres obras que hemos comentado exponen unos principios similares, no podemos pasar por alto el contraste que existe entre los dos tipos de propuesta que se ofrecen, de un lado en Razonamiento inagotable y Los Arcángeles y, de otro en Valentín. Esta última implica la realización extrema de lo prohibido en los dominios de la vida. Ese deseo de «eternizarse en la contemplación de la imagen amada», común a todos los personajes, es alcanzado únicamente por Richard.

47. El parentesco con Cernuda, que aparece en muchos otros aspectos, es aquí muy claro. Armando LOPEZ CASTRO, «Etica y poesía en Cernuda», Cuadernos para Investigación de la Literatura Hispánica, Madrid, Seminario «Menéndez Pelayo», núm. 8, 1987, pp. 77-78, se ha referido, siguiendo a José Angel Valente, a «esa sociología poética de la soledad, tan poco incorporada por nuestra tradición» y que ha adoptado Cernuda. 
Su autoafirmación final en el crimen cometido y la muerte que espera, pueden parecer bastante contrarias a una ética y un pensamiento «razonadores». Es, en definitiva, una sublimación lícita en el arte -como en la filosofía amorosa de Dante-, y dentro de un marco más específico, en la tragedia. El racionalismo de Gil-Albert no se substrae al mundo del mito. 